\title{
EFEITO DO RECALL DO PATROCÍNIO MÁSTER NOS FATORES DE CONSUMO DE BENS E SERVIÇOS DE UM CLUBE DE FUTEBOL
}

\author{
Effect of Master sponsorship recall on the factors of consumption of \\ goods and services of a football Club
}

Thiago Bruno Jesus Silva

E-mail: thiagobsilva@ufgd.edu.br

Doutorando em Contabilidade na Universidade Federal de Santa Catarina; Mestre em Contabilidade pela Fundação Universidade Regional de Blumenau; Professor no Curso de Ciências Contábeis da Universidade Federal da Grande Dourados.

Endereço para contato: Rodovia Dourados, Km 12, Zona Rural, 89012-900, Dourados, Mato Grosso do Sul, Brasil. https://orcid.org/0000-0002-1128-6601

Luís Antonio Lay E-mail: luisantoniolay@gmail.com

Mestre em Contabilidade pela Fundação Universidade Regional de Blumenau; Graduado em Matemática pela Fundação Universidade Regional de Blumenau; Professor nos Cursos de Engenharia Civil e Administração da Universidade do Contestado. https://orcid.org/0000-0003-1992-2016

Cristian Baú Dal Magro

E-mail: cristianbaumagro@gmail.com

Doutor em Contabilidade e Administração pela Fundação Universidade Regional de Blumenau; Mestre em Ciências Contábeis pela Fundação Universidade Regional de Blumenau; Professor no Curso de Mestrado em Ciências Contábeis e Administração da Universidade Comunitária da Região de Chapecó. https://orcid.org/0000-0002-7609-5806

Denise Isabel Rizzi

E-mail: deniserizzi@unochapeco.edu.br Mestre em Ciências Contábeis e Administração pela

Universidade Comunitária da Região de Chapecó; Doutoranda em Contabilidade na Universidade Federal de Santa Catarina; Pesquisadora na Federação das Indústrias do Estado de Santa Catarina. https://orcid.org/0000-0002-0684-9940

Rafael Ferla E-mail: rafaelferla@live.com Mestre em Contabilidade pela Fundação Universidade Regional de Blumenau; Graduado em Ciências Contábeis pela Faculdade de Itapiranga; Professor no Curso de Ciências Contábeis da Faculdade Santa Rita - Campus Palmitos. https://orcid.org/0000-0001-9260-0107

Artigo recebido em 11 de agosto de 2018. Aceito em 28 de março de 2019. 


\section{Resumo}

O amor pelo futebol é um sentimento enraizado no povo brasileiro. Esse sentimento/carisma pelo esporte se reflete na aquisição assídua de produtos vinculados aos clubes esportivos. Desse modo, o objetivo desta investigação foi identificar a relação do recall do patrocínio Máster nos fatores explicativos para o consumo de bens e serviços do Esporte Clube Vitória. A amostra da pesquisa foi composta por 746 respondentes. A coleta de dados ocorreu entre os meses de dezembro de 2017 e julho de 2018 pela plataforma Google Docs. A análise dos dados foi elaborada com o uso da estatística descritiva e pela análise de regressão logística binária. Conclui-se que o recall do patrocínio Máster se torna mais efetivo pelo estímulo, como ocorrido nos recalls da empresa OAS e da Caixa Econômica Federal, em que ambos podem ter exercido efeito moderador, do envolvimento para o consumo dos produtos e serviços, em razão dos títulos do campeonato baiano. Esses achados ajudam na determinação de características que explicam o hábito de consumo dos torcedores, bem como no efeito que o recall do patrocínio Máster exerce na relação entre os fatores explicativos e o hábito de consumo dos torcedores para os produtos ofertados pelos clubes de futebol.

Palavras-chave: Recall do patrocínio. Produtos/serviços esportivos. Fatores do consumo. Torcedores.

\section{Abstract}

The love of football is a feeling rooted in the Brazilian people. This feeling/charisma for the sport is reflected in the assiduous acquisition of products linked to sports clubs. In this way, the objective of this investigation was to identify the relation of the Master sponsorship recall in the explanatory factors for the consumption of goods and services of the Esporte Clube Vitória. The survey sample consisted of 746 respondents. Data collection took place between the months of December 2017 and July 2018 by the Google Docs platform. Data analysis was performed using descriptive statistics and binary logistic regression analysis. It is concluded that the Master sponsorship recall is made more effective by the stimulus, as occurred in the recall of the company OAS and Caixa Econômica Federal, both of which may have had a moderating effect, from the involvement in the consumption of products and services, as a function of Bahian championship titles. These findings help to determine the characteristics that explain the consumption habits of the fans, as well as the effect that the Master sponsorship recall has on the relation between the explanatory factors and the consumption habits of the fans for the products offered by the soccer clubs.

Keywords: Recall of sponsorship. Sports products/services. Consumption factors. Fans.

\section{INTRODUÇÃO}

De acordo com o Relatório Final do Plano de Modernização do Futebol Brasileiro da Fundação Getúlio Vargas e da Confederação Brasileira de Futebol ([FGV, CBF], 2000), o futebol mundial movimenta, em média, cerca de 250 bilhões de dólares anuais. No Brasil, é uma atividade econômica com grande capacidade de gerar emprego e tem efeito multiplicador maior que vários setores tradicionais, contabilizando, em média, aproximadamente 300 mil empregos diretos; 30 milhões de praticantes (formais e não formais); 580 mil participantes em 13 mil times que participam de jogos organizados (esporte formal); 580 estádios com capacidade para abrigar mais de 5,5 milhões de torcedores; entre outros fatores. 
Diante do fascínio e da demanda de consumo por parte dos torcedores, os clubes de futebol investem não apenas no departamento de futebol, mas também no departamento de gestão, administração e marketing esportivo (Pacheco, 2017). Além das equipes esportivas, diversas empresas ligadas aos produtos esportivos buscam atrair esse público por meio do patrocínio esportivo.

Nos últimos anos, o patrocínio esportivo tem sido uma das ferramentas de marketing que mais tem se desenvolvido. Seu investimento anual aumentou mais de 130\%, entre 1996 e 2004, quando atingiu US\$21 bilhões mundialmente (leg Sponsorship Report [IEG], 2004). Em 2006, o somatório de investimentos em patrocínio, dos 10 maiores anunciantes mundiais, alcançou o patamar de US\$2,5 bilhões (Sport Business, 2007). Esse volume de investimentos é reflexo do resultado financeiro favorável das empresas, obtido pelo incremento nas vendas de bens e serviços aos torcedores dos clubes de futebol.

Apesar de o marketing esportivo promover a alavancagem nas vendas de produtos dos clubes de futebol, também se faz necessário considerar que existem outros fatores, inatos ao ser humano, que podem motivar os torcedores a comprarem esses bens e serviços. Pacheco (2017) comenta que essas características dos indivíduos, formadas pelo gênero, idade, escolaridade, ser sócio do clube, ser membro da torcida organizada e o costume de praticar esportes, podem intensificar a motivação dos torcedores para a aquisição dos produtos e serviços ofertados pelo seu time de coração.

Além disso, existem fatores explicativos do consumo dos torcedores por produtos do clube de futebol, os quais podem estar relacionados com o acompanhamento do time (exposição), envolvimento com o resultado do clube, bem como com as discussões e debates sobre a partida (envolvimento), domínio pelo futebol, gostando do esporte e assistindo constantemente aos jogos (domínio futebol), e com a percepção do torcedor sobre as marcas expostas pelo clube nos jogos (similaridade) (Gwinner \& Eaton, 1999; Gwinner \& Swanson, 2003; Grohs, Wagner, \& Vsetecka, 2004; Grynberg \& Rocha, 2010; Pacheco, 2017).

De maneira complementar, as marcas auxiliam o consumidor na identificação da origem do bem ou serviço, além de agregarem valor na diferenciação de produtos com características similares (Kotler \& Keller, 2006). Assim, a conexão do indivíduo/torcedor com uma marca tem intensificado as intenções de compra de determinado produto ou serviço.

O investimento em patrocínio esportivo, geralmente, tem como objetivo principal o reconhecimento da marca, também chamado de recall. No contexto esportivo, o termo consiste na parcela de visibilidade e reconhecimento da marca patrocinadora, decorrente de variadas formas de exposição (Scharf, 2010). O termo recall tem sido definido pela mensagem que fica retida na memória de uma pessoa exposta a estímulos. Assim, quanto maior a capacidade de retenção, maior será a eficiência na comunicação (Grynberg \& Rocha, 2010). 
Para tanto, existem fatores que motivam os torcedores ao consumo de produtos $e$ serviços ofertados pelos clubes de futebol, contudo, existe também o recall assertivo dos patrocinadores sendo comprovado como intensificador de compra dos torcedores, conforme comprovado por Pacheco (2017). Dessa forma, o recall do patrocínio Máster pode intensificar ou minimizar a relação dos fatores explicativos ao consumo de produtos ou serviços.

Com base nesse contexto e a partir dessa plataforma teórica, foi desenvolvido o seguinte problema: qual a relação do recall do patrocínio Máster nos fatores explicativos para o consumo de bens e serviços do Esporte Clube Vitória? Nesse sentido, o objetivo do estudo foi identificar a relação do recall do patrocínio Máster nos fatores explicativos para o consumo de bens e serviços do Esporte Clube Vitória.

Apesar da demanda de investimentos para promover a venda de produtos esportivos e similares, ainda não é claro o motivo que leva os torcedores ao consumo de bens e serviços e ao acompanhamento dos jogos do seu time de coração (Adamson, Jones, \& Tapp, 2006). Nessas circunstâncias, a contribuição da pesquisa versa em promover os aspectos que estimulam o consumo de produtos e serviços ofertados pelos clubes de futebol. Os resultados também atestam que os patrocinadores podem ter resultados satisfatórios com a manutenção ou ampliação dos investimentos em clubes de futebol, desde que atinjam os consumidores praticantes de esportes, representantes das torcidas organizadas.

No mais, o estudo se justifica pela explicação dos motivos que os torcedores do Esporte Clube Vitória consideram ao consumir bens e serviços relacionados ao time do seu coração, - que pode proporcionar fonte detalhada de informação aos usuários, como os próprios clubes esportivos, bem como as empresas patrocinadoras. Nesse aspecto, apresenta-se como esses consumidores reagem e quais são suas preferências. Nessa linha, Fleury, Alejandro, e Feldmann (2014) afirmam que os clubes precisam encontrar um meio para realizar o processo de troca com seus torcedores, para, assim, melhorar suas receitas e aumentar o número de seguidores.

Esta pesquisa se diferencia das demais por determinar que as características dos indivíduos podem ser utilizadas como fatores explicativos do hábito de consumo dos torcedores, bem como pelo fato de que o recall do patrocínio Máster pode exercer um efeito de moderação sobre a relação entre os fatores explicativos e o hábito de consumo dos torcedores.

\section{FUTEBOL E O MARKETING}

Em um cenário de tamanha concorrência, as empresas precisam estar sempre focadas em um atendimento cada vez mais eficiente aos clientes, para, assim, atenderem às suas 
exigências e conquistarem a fatia de um mercado altamente disputado. Um dos meios mais competentes para atingir esse objetivo é por meio da introdução dos processos de marketing.

O marketing é um conjunto de procedimentos para criar, manter e transferir valor aos clientes e serve para manter a comunicação de todos os que estão ligados diretamente ou indiretamente com a empresa. Inclui atividades como análise, planejamento, implementação e controle das necessidades dos clientes que visam sempre à lucratividade e à qualidade na prestação dos serviços e dos produtos oferecidos (Hooley, Saunders, \& Piercy, 2005).

Em meio às linhas do marketing, uma categoria que está crescente consideravelmente nos últimos anos é o marketing no esporte, popularmente chamada de marketing esportivo. Teve seu início nos anos 1978, no Advertising Age, com o propósito de explicar as estratégias de empresas para promover seus bens e serviços por meio do esporte. Desde o início, o marketing no esporte tinha em suas atividades os benefícios subjetivos que os produtos podem proporcionar ao ser diferenciais significativos na ação de compra, fixação de marca e criação de uma identidade para os consumidores (Malagrino, 2011; Pacheco, 2017).

O estudo do marketing esportivo inclui tanto as estratégias de gestão quanto os meios de comercialização e divulgação de academias, clubes, ligas esportivas, entre outros. A escolha por esse nicho de mercado baseia-se em alguns benefícios que o esporte proporciona às marcas, como: emoção do consumidor, oportunidade de capitalização de apoio e lealdade do torcedor, potencial de compartilhar e identificar o mercado-alvo, oportunidade de exposição da marca e do produto com eficiente custo-benefício, alinhamento da personalidade da marca ao sucesso do clube ou atleta, entre outros (Morgan \& Summers, 2008; Russi, 2014).

O Brasil é popularmente conhecido como o País do futebol e, segundo Bezerra e Luna (2017), o futebol está intimamente ligado ao mercado. Em linha, Marques (2007) afirma que esse esporte tem relação de consumo com os seus torcedores, que se tornaram público-alvo para um mercado cada vez mais almejado. Segundo Carvalho (2001), o futebol, organizado na esfera de clubes, está se tornando uma organização com potencial para promover eficiência, rentabilidade e competitividade de grandes marcas patrocinadoras.

Dessa forma, investir em um clube de futebol pode ser uma estratégia de marketing adequada para as empresas, pois esse tipo de ação busca, por intermédio de atividades integradas, direcionar e deliberar a forma como a organização alocará seus recursos para atender à demanda dos clientes (Varadarajan, 2011). No entanto, apesar das características próprias, o marketing esportivo pouco difere do marketing, a não ser nas peculiaridades do segmento esportivo que envolvem aspectos como: produto, demanda, desejo, necessidade, valor, satisfação, qualidade e mercado (Malagrino, 2011).

As marcas líderes podem optar por investir no ramo esportivo para explorar a opinião pública de atletas elou equipes, buscando resultados positivos para a sua própria imagem. 
Portanto, o marketing esportivo torna-se uma ferramenta que diferencia marcas e produtos, por atingir o espectador (consumidor) em seu momento de lazer e euforia (Malagrino, 2011).

\section{PATROCÍNIO ESPORTIVO}

O patrocínio é um investimento em atividades que oferecem como contrapartida o acesso a uma exposição comercial (Meenaghan, 2001). Javalgi, Traylor, Gross, e Lampman (1994) definem o patrocínio pela subscrição de um evento especial com o propósito de apoiar os objetivos de uma empresa. O objetivo central do patrocinador, segundo Javalgi et al. (1994) e Rocha e Campos (2010), relaciona-se com: promoção da imagem, aumento de vendas e construção de relacionamentos. Desse modo, para ter sucesso em seus investimentos, o patrocinador depende da lembrança favorável de sua marca pelo consumidor (Grynberg \& Rocha, 2010).

No patrocínio esportivo existem vários fatores capazes de influenciar a lembrança favorável do consumidor perante uma marca: a exposição, que se relaciona com o maior envolvimento dos torcedores com a mensagem comunicada (Grohs, Wagner, \& Vsetecka, 2004); o envolvimento, por provocar uma relação de identificação, motivação, engajamento e afiliação com uma equipe esportiva (Grynberg \& Rocha, 2010); e a similaridade, que envolve a percepção do consumidor sobre a relação entre patrocinado e patrocinador (Gwinner \& Swanson, 2003; Grynberg \& Rocha, 2010).

O patrocínio esportivo é bem-visto pelas organizações por atingir o público em um momento de vulnerabilidade, em que está mais propenso a receber a mensagem que a empresa deseja transmitir. $O$ investimento em clubes esportivos na forma de patrocínio resulta na exposição de uma marca a um custo relativamente baixo se comparado com as outras mídias tradicionais (Zinger \& O'Reilly, 2010). Outra potencialidade do investimento de empresas no esporte é o espaço cativo desse ambiente na mídia tradicional (Scharf, 2010).

Dessa forma, o patrocínio esportivo inclui várias atividades de comunicação, o qual se utiliza do esporte e do estilo de vida das pessoas para atingir o seu público. Com o passar dos anos, houve grandes modificações nesse movimento de publicidade por meio de times de futebol, principalmente pela profissionalização do esporte, realidade socioeconômica do País e elementos culturais da população frente à participação em torcidas organizadas e mudanças nos hábitos de consumo. Desse modo, pelo futebol brasileiro se busca cada vez mais a aplicação de estratégias de emoção, exposição e vendas com vistas a aumentar o consumo de produtos esportivos de determinadas marcas (Benazzi \& Borges, 2009; Pacheco, 2017).

No campo do consumo de bens e serviços relacionados aos clubes esportivos, alguns estudos se dedicaram a pesquisar como foram os casos de Gwinner e Eaton (1999), Gwinner e Swanson (2003), Grohs, Wagner, e Vsetecka (2004), Grynberg e Rocha (2010) e Pacheco 
(2017). Tais investigações contribuíram na construção adequada do constructo desta pesquisa. Entretanto, essas investigações não consideraram o recall como efeito moderador na relação já existente entre os fatores explicativos do consumo, o que motiva a realização desta pesquisa.

\section{TRAJETÓRIA METODOLÓGICA}

A pesquisa foi caracterizada como descritiva para os objetivos, de levantamento nos procedimentos e, por fim, de cunho quantitativo na abordagem do problema. Destaca-se a escolha do Esporte Clube Vitória como ambiente de estudo. Esse clube foi fundado no ano 1899, na Cidade de Salvador, BA. Está entre os 50 clubes mais valiosos do Continente Americano, de acordo com a Forbes Brasil (2018). É um dos principais times do Brasil e obteve consideráveis investimentos nos últimos anos, sendo que em 2017 recebeu o montante de $R \$ 5.689 .619,00$ em patrocínios e, em 2016, o montante de $R \$ 8.826 .000,00$.

A acessibilidade foi determinante para a elaboração da investigação, o que foi importante para se definir a escolha do clube. Além disso, apesar do Esporte Clube Vitória não ser um clube considerado grande no futebol brasileiro, atinge um número expressivo de torcedores, e, também, representa uma região com grande potencial de mercado consumidor para seus os produtos/serviços.

A coleta de dados ocorreu entre os meses de dezembro de 2017 e julho de 2018 pela plataforma Google Docs. O link foi enviado por meio das redes sociais Facebook e WhatsApp. No Facebook, solicitou-se auxílio para a divulgação aos proprietários de grupos de torcedores ligados ao clube e para a página de jornalismo Correio Ba-Vi. No WhatsApp, solicitou-se o subsídio de jornalistas (setoristas ligados ao clube) para a divulgação em suas listas de transmissão. Desse modo, obtiveram-se 746 respondentes.

Para a definição do instrumento de coleta de dados foram elaboradas adaptações no questionário já validado no estudo de Grynberg e Rocha (2010), os quais verificaram a propensão da lembrança e o índice de recall dos consumidores a respeito das marcas patrocinadoras da seleção brasileira. Assim, por se tratar de um clube com características regionais, os eventos relacionados à dimensão Exposição (assistir aos jogos da seleção pela televisão) foram alterados pela participação dos torcedores no estádio quando o jogo do Vitória é realizado em Salvador, e também pela frequência com que são assistidos os jogos do Vitória pelos meios de comunicação, quando o jogo é em outras localidades.

Vale destacar que o instrumento já havia sido adaptado e utilizado pelo estudo de Pacheco (2017), o qual analisou a probabilidade de o recall da marca dos patrocinadores e de os constructos exposição, envolvimento, interesse e similaridade influenciarem no consumo de bens e serviços relacionados ao Joinville Esporte Clube (JEC). 
Nesse sentido, na Tabela 1 apresenta-se o constructo do estudo com relação às características dos respondentes, hábito de consumo de bens e serviços do clube, recall dos patrocinadores, e, por fim, fatores explicativos do consumo de bens e serviços.

A análise dos resultados foi elaborada com o uso da estatística descritiva nas respostas obtidas pela aplicação dos questionários. Posteriormente, utilizou-se a regressão logística binária para avaliar o objetivo da pesquisa. Agresti e Finlay (2012) explica que o modelo de regressão logística é usado quando a variável dependente possui uma ordenação entre as suas categorias. Para tanto, delineou-se como variável dependente do estudo o hábito de consumo de produtos e serviços do clube, sendo esta caracterizada como uma variável dummy 1 para o consumidor potencial e 0 caso contrário; as demais variáveis foram determinadas como explicativas e aplicadas aos modelos que comprovarão os achados.

Destaca-se que a variável origem, determinada como de múltipla escolha no constructo, foi delineada como dummy 1 para aqueles que nasceram e residem em Salvador e 0 caso contrário; isso também ocorreu com o recall dos patrocinadores, sendo que o respondente que acertou o recall espontâneo foi categorizado com dummy l e 0 caso contrário; o respondente que acertou o recall da OAS foi categorizado com dummy 1 e 0 caso contrário; e, por fim, o respondente que acertou o recall da Caixa Econômica Federal foi categorizado com dummy 1 e 0 caso contrário.

Tabela 1

Constructo da pesquisa que representa o instrumento utilizado para a coleta de dados

\begin{tabular}{|c|c|c|c|c|}
\hline Dimensão & Sigla & Variáveis & Mensuração & Estudos Anteriores \\
\hline \multirow{8}{*}{$\begin{array}{l}\text { Caracterização } \\
\text { do respondente }\end{array}$} & GEN & Gênero & $\begin{array}{l}\text { Dicotômica } \\
\text { (Masculino (0) } \\
\text { - Feminino (1)) }\end{array}$ & \multirow{8}{*}{ Pacheco (2017) } \\
\hline & IDADE & Idade & Múltipla & \\
\hline & ORG & Origem & Múltipla & \\
\hline & ESCO & Escolaridade & Múltipla & \\
\hline & RENDA & Renda individual & Múltipla & \\
\hline & PRAT & Praticante de esporte & $\begin{array}{l}\text { Dicotômica } \\
\text { (Sim - Não) }\end{array}$ & \\
\hline & SOC & Sócio do clube & $\begin{array}{l}\text { Dicotômica } \\
\text { (Sim - Não) }\end{array}$ & \\
\hline & TORC & Membro de torcida organizada & $\begin{array}{l}\text { Dicotômica } \\
\text { (Sim - Não) }\end{array}$ & \\
\hline $\begin{array}{l}\text { Hábito de } \\
\text { consumo }\end{array}$ & CONS & $\begin{array}{l}\text { Quando uma empresa começa a patro- } \\
\text { cinar o Vitória, ela já pode me conside- } \\
\text { rar um consumidor potencial? Possível } \\
\text { comprador de um produto vendido pelo } \\
\text { patrocinador. }\end{array}$ & $\begin{array}{l}\text { Dicotômica } \\
\text { (Sim - Não) }\end{array}$ & $\begin{array}{l}\text { Gwinner e Eaton } \\
\text { (1999); Gwinner e } \\
\text { Swanson (2003); } \\
\text { Grohs et al. (2004); } \\
\text { Grynberg e Rocha } \\
\text { (2010); Pacheco } \\
\text { (2017) }\end{array}$ \\
\hline
\end{tabular}




\begin{tabular}{|c|c|c|c|c|}
\hline Dimensão & Sigla & Variáveis & Mensuração & Estudos Anteriores \\
\hline \multirow{3}{*}{$\begin{array}{l}\text { Recall dos pa- } \\
\text { trocinadores }\end{array}$} & ESP & $\begin{array}{l}\text { Na sua visão, quem é o patrocinador } \\
\text { Máster do Vitória em } 2017 \text { ? - Patroci- } \\
\text { nador Máster - marca em destaque na } \\
\text { camisa de jogo. }\end{array}$ & $\begin{array}{l}\text { Dicotômica } \\
\text { (Asserto l; erro } \\
\text { O). }\end{array}$ & \multirow{3}{*}{$\begin{array}{l}\text { Gwinner e Eaton } \\
\text { (1999); Gwinner e } \\
\text { Swanson (2003); } \\
\text { Grohs et al. (2004); } \\
\text { Grynberg e Rocha } \\
\text { (2010); Pacheco } \\
\text { (2017) }\end{array}$} \\
\hline & OAS & $\begin{array}{l}\text { No título do campeonato baiano de } \\
\text { 2013, qual dessas empresas era o patro- } \\
\text { cinador Máster? }\end{array}$ & $\begin{array}{l}\text { Dicotômica } \\
\text { (Asserto l; erro } \\
\text { O). }\end{array}$ & \\
\hline & CAIXA & $\begin{array}{l}\text { No título do campeonato baiano de } \\
2016 \text {, qual dessas empresas era o pa- } \\
\text { trocinador Máster? }\end{array}$ & $\begin{array}{l}\text { Dicotômica } \\
\text { (Asserto l; erro } \\
\text { O). }\end{array}$ & \\
\hline \multirow{2}{*}{ Exposição } & EXPI & $\begin{array}{l}\text { Acompanho os jogos do Esporte Clube } \\
\text { Vitória no Barradão (Estádio do Vitó- } \\
\text { ria). }\end{array}$ & $\begin{array}{l}\text { Escala likert } 5 \\
\text { pontos }\end{array}$ & \multirow{2}{*}{$\begin{array}{l}\text { Gwinner e Eaton } \\
\text { (1999); Gwinner e } \\
\text { Swanson (2003); } \\
\text { Grohs et al. (2004); } \\
\text { Grynberg e Rocha } \\
\text { (2010); Pacheco } \\
\text { (2017) }\end{array}$} \\
\hline & EXP2 & $\begin{array}{l}\text { Quando o jogo é em outra cidade, } \\
\text { assisto pela televisão ou pela internet. }\end{array}$ & $\begin{array}{l}\text { Escala likert } 5 \\
\text { pontos }\end{array}$ & \\
\hline \multirow{4}{*}{ Envolvimento } & ENV1 & $\begin{array}{l}\text { Antes ou depois do jogo, acompanho } \\
\text { discussões e reportagens do tipo "me- } \\
\text { sas- redondas" e "melhores momentos". }\end{array}$ & $\begin{array}{l}\text { Escala likert } 5 \\
\text { pontos }\end{array}$ & \multirow{4}{*}{$\begin{array}{l}\text { Gwinner e Eaton } \\
\text { (1999); Gwinner e } \\
\text { Swanson (2003); } \\
\text { Grohs et al. (2004); } \\
\text { Grynberg e Rocha } \\
\text { (2010); Pacheco } \\
\text { (2017) }\end{array}$} \\
\hline & ENV2 & $\begin{array}{l}\text { Depois do jogo, costumo participar de } \\
\text { discussões com amigos. }\end{array}$ & $\begin{array}{l}\text { Escala likert } 5 \\
\text { pontos }\end{array}$ & \\
\hline & ENV3 & $\begin{array}{l}\text { Quando o Vitória perde, fico chateado } \\
\text { ou irritado no dia seguinte ao jogo? }\end{array}$ & $\begin{array}{l}\text { Escala likert } 5 \\
\text { pontos }\end{array}$ & \\
\hline & ENV4 & $\begin{array}{l}\text { Quando vejo alguém criticando o } \mathrm{Vi} \text { - } \\
\text { tória (como imprensa, amigos, etc.) me } \\
\text { sinto incomodado. }\end{array}$ & $\begin{array}{l}\text { Escala likert } 5 \\
\text { pontos }\end{array}$ & \\
\hline \multirow{3}{*}{$\begin{array}{l}\text { Domínio fute- } \\
\text { bol }\end{array}$} & DFl & Eu adoro futebol. & $\begin{array}{l}\text { Escala likert } 5 \\
\text { pontos }\end{array}$ & \multirow{3}{*}{$\begin{array}{l}\text { Gwinner e Eaton } \\
\text { (1999); Gwinner e } \\
\text { Swanson (2003); } \\
\text { Grohs et al. (2004); } \\
\text { Grynberg e Rocha } \\
\text { (2010); Pacheco } \\
\text { (2017) }\end{array}$} \\
\hline & DF2 & $\begin{array}{l}\text { Costumo pensar, ler ou falar sobre } \\
\text { futebol diariamente. }\end{array}$ & $\begin{array}{l}\text { Escala likert } 5 \\
\text { pontos }\end{array}$ & \\
\hline & DF3 & Eu assisto futebol sempre que posso. & $\begin{array}{l}\text { Escala likert } 5 \\
\text { pontos }\end{array}$ & \\
\hline \multirow{2}{*}{ Similaridade } & SIMI & $\begin{array}{l}\text { Quando assisto aos jogos do Vitória, } \\
\text { vejo produtos dos patrocinadores sendo } \\
\text { utilizados pelos atletas. }\end{array}$ & $\begin{array}{l}\text { Escala likert } 5 \\
\text { pontos }\end{array}$ & \multirow{2}{*}{$\begin{array}{l}\text { Gwinner e Eaton } \\
\text { (1999); Gwinner e } \\
\text { Swanson (2003); } \\
\text { Grohs et al. (2004); } \\
\text { Grynberg e Rocha } \\
\text { (2010); Pacheco } \\
\text { (2017) }\end{array}$} \\
\hline & SIM2 & $\begin{array}{l}\text { As ideias que eu associo aos patrocina- } \\
\text { dores são semelhantes às ideias que eu } \\
\text { associo ao Vitória. }\end{array}$ & $\begin{array}{l}\text { Escala likert } 5 \\
\text { pontos }\end{array}$ & \\
\hline
\end{tabular}

\section{ANÁLISE E DISCUSSÕES DOS RESULTADOS}

Inicialmente, com o objetivo de compreender as características da amostra analisada, a estatística descritiva apresenta a caracterização dos respondentes. A seguir, na Tabela 2, apresenta-se a estatística descritiva da caracterização dos respondentes e o hábito de consumo do potencial comprador: 
Tabela 2

Estatística descritiva da caracterização dos respondentes

\begin{tabular}{|c|c|c|}
\hline Gênero & Quantidade & Percentual \\
\hline Masculino & 705 & $94,5 \%$ \\
\hline Feminino & 41 & $5,5 \%$ \\
\hline Idade & Quantidade & Percentual \\
\hline Até 18 & 106 & $14,21 \%$ \\
\hline De 19 a 25 anos & 241 & $32,3 \%$ \\
\hline De 26 a 35 anos & 261 & $34,99 \%$ \\
\hline De 36 a 45 anos & 91 & $12,2 \%$ \\
\hline Mais de 45 anos & 47 & $6,3 \%$ \\
\hline Origem & Quantidade & Percentual \\
\hline Nasci e moro em Salvador, BA & 485 & $65,01 \%$ \\
\hline Nasci em Salvador, BA, mas não moro mais na Cidade & 78 & $10,46 \%$ \\
\hline Nasci em outra cidade, mas moro em Salvador, BA & 72 & $9,65 \%$ \\
\hline Nasci e moro em outra cidade & 111 & $14,88 \%$ \\
\hline Grau de instrução & Quantidade & Percentual \\
\hline Ensino fundamental incompleto & 42 & $5,63 \%$ \\
\hline Ensino fundamental completo & 182 & $24,4 \%$ \\
\hline Superior incompleto & 248 & $33,24 \%$ \\
\hline Superior completo & 175 & $23,46 \%$ \\
\hline Pós-graduação incompleta & 23 & $3,08 \%$ \\
\hline Pós-graduação completa & 76 & $10,19 \%$ \\
\hline Renda individual & Quantidade & Percentual \\
\hline Não tenho renda (dependo financeiramente de outra pessoa) & 142 & $19,03 \%$ \\
\hline Até $\mathrm{R} \$ 937,00$ & 110 & $14,75 \%$ \\
\hline De $R \$ 937,00$ a $R \$ 2.811,00$ & 264 & $35,39 \%$ \\
\hline De $\mathrm{R} \$ 2.811,00$ a $\mathrm{R} \$ 4.685,00$ & 106 & $14,21 \%$ \\
\hline De $R \$ 4.685,00$ a $R \$ 6.559,00$ & 49 & $6,57 \%$ \\
\hline De $R \$ 6.559,00$ a $R \$ 8.433,00$ & 24 & $3,22 \%$ \\
\hline Mais de $\mathrm{R} \$ 8.433,00$ & 51 & $6,84 \%$ \\
\hline Sou praticante de esporte & Quantidade & Percentual \\
\hline Não & 190 & $25,47 \%$ \\
\hline Sim & 556 & $74,53 \%$ \\
\hline Sou sócio do Clube & Quantidade & Percentual \\
\hline Não & 467 & $62,6 \%$ \\
\hline Sim & 279 & $37,4 \%$ \\
\hline Sou membro da torcida organizada & Quantidade & Percentual \\
\hline Não & 695 & $93,16 \%$ \\
\hline Sim & 51 & $6,84 \%$ \\
\hline Total de respondentes & 746 & \\
\hline
\end{tabular}

Conforme evidenciado na Tabela 2, há a predominância entre os torcedores do gênero masculino, fato caracterizado pelo fenômeno cultural observado no Brasil, onde há um maior envolvimento do gênero masculino no acompanhamento regular das partidas de 
futebol, conforme corrobora Souza (1996). Observa-se que os respondentes possuem entre 19 e 25 anos, e entre 26 e 35 anos. Os achados indicam que aproximadamente 80,97\% dos respondentes não dependem financeiramente de terceiros, ou seja, possuem alguma renda individual. De maneira geral, apesar da renda baixa obtida nas respostas da maioria dos respondentes, destaca-se que grande parcela apresenta independência financeira para adquirir produtos e serviços do clube de futebol.

Ademais, verifica-se que a maior parte dos respondentes nasceram e continuam residindo em Salvador, BA. Portanto, infere-se que grande parte dos respondentes conhecem e conviveram com a história do Esporte Clube Vitória. Nesse sentido, essa parcela de torcedores pode apresentar um sentimento diferenciado sobre o clube que faria com que tivessem uma maior tendência para a aquisição dos produtos e serviços.

Demonstra-se que mais de $69 \%$ dos torcedores possuem grau elevado de escolaridade, enquanto $30 \%$ possuem ensino médio completo ou incompleto. Neste ínterim, a educação faz com que os torcedores tenham uma visualização diferenciada sobre o interesse dos patrocinadores e do clube quanto à propagação das vendas dos seus produtos e serviços.

No tocante às características de ligação com o esporte, destaca-se que $74,53 \%$ dos respondentes costumam praticar esportes e, portanto, apresentam maior tendência para a aquisição de materiais esportivos e, por estarem vinculados à torcida do Esporte Clube Vitória, teriam maior probabilidade para a aquisição dos produtos oferecidos pelos patrocinadores.

A Tabela 3 mostra a estatística descritiva de associação entre a caracterização dos respondentes e o hábito de potencial comprador de produtos do Esporte Clube Vitória pelos respondentes da pesquisa:

Tabela 3

Estatística descritiva de associação entre a caracterização dos respondentes e o hábito de consumo do potencial comprador

\begin{tabular}{|c|c|c|c|c|c|}
\hline \multirow{2}{*}{$\begin{array}{ll} & \text { Potencial comprador } \\
\text { Gênero } & \end{array}$} & \multicolumn{2}{|c|}{ Não } & \multicolumn{2}{|c|}{ Sim } & \multirow[t]{2}{*}{ Total } \\
\hline & Quant. & $\%$ & Quant. & $\%$ & \\
\hline Masculino & 220 & $31,21 \%$ & 485 & $68,79 \%$ & 705 \\
\hline Feminino & 16 & $39,02 \%$ & 25 & $60,98 \%$ & 41 \\
\hline Idade & Quant. & $\%$ & Quant. & $\%$ & \\
\hline Até 18 & 37 & $34,91 \%$ & 69 & $65,09 \%$ & 106 \\
\hline De 19 a 25 anos & 81 & $33,61 \%$ & 160 & $66,39 \%$ & 241 \\
\hline De 26 a 35 anos & 76 & $29,12 \%$ & 185 & $70,88 \%$ & 261 \\
\hline De 36 a 45 anos & 29 & $31,87 \%$ & 62 & $68,13 \%$ & 91 \\
\hline Mais de 45 anos & 13 & $27,66 \%$ & 34 & $72,34 \%$ & 47 \\
\hline Origem & Quant. & $\%$ & Quant. & $\%$ & \\
\hline Nasci e moro em Salvador, BA & 163 & $33,61 \%$ & 322 & $66,39 \%$ & 485 \\
\hline $\begin{array}{l}\text { Nasci em Salvador, BA, mas não moro } \\
\text { mais na Cidade }\end{array}$ & 22 & $28,21 \%$ & 56 & $71,79 \%$ & 78 \\
\hline
\end{tabular}




\begin{tabular}{|c|c|c|c|c|c|}
\hline \multirow{2}{*}{$\begin{array}{l}\text { Potencial comprador } \\
\text { Nasci em outra cidade, mas moro em } \\
\text { Salvador, BA }\end{array}$} & \multicolumn{2}{|c|}{ Não } & \multicolumn{2}{|c|}{ Sim } & \multirow{2}{*}{72} \\
\hline & 20 & $27,78 \%$ & 52 & $72,22 \%$ & \\
\hline Nasci e moro em outra cidade & 31 & $27,93 \%$ & 80 & $72,07 \%$ & 111 \\
\hline Grau de instrução & Quant. & $\%$ & Quant. & $\%$ & \\
\hline Ensino fundamental incompleto & 16 & $38,1 \%$ & 26 & $61,9 \%$ & 42 \\
\hline Ensino fundamental completo & 57 & $31,32 \%$ & 125 & $68,68 \%$ & 182 \\
\hline Superior incompleto & 74 & $29,84 \%$ & 174 & $70,16 \%$ & 248 \\
\hline Superior completo & 61 & $34,86 \%$ & 114 & $65,14 \%$ & 175 \\
\hline Pós-graduação incompleto & 6 & $26,09 \%$ & 17 & $73,91 \%$ & 23 \\
\hline Pós-graduação completo & 22 & $28,95 \%$ & 54 & $71,05 \%$ & 76 \\
\hline Renda individual & Quant. & $\%$ & Quant. & $\%$ & \\
\hline $\begin{array}{l}\text { Não tenho renda (dependo de outra } \\
\text { pessoa) }\end{array}$ & 43 & $30,28 \%$ & 99 & $69,72 \%$ & 142 \\
\hline Até $\mathrm{R} \$ 937,00$ & 41 & $37,27 \%$ & 69 & $62,73 \%$ & 110 \\
\hline De $R \$ 937,00$ a $R \$ 2.811,00$ & 84 & $31,82 \%$ & 180 & $68,18 \%$ & 264 \\
\hline De $R \$ 2.811,00$ a $R \$ 4.685,00$ & 33 & $31,13 \%$ & 73 & $68,87 \%$ & 106 \\
\hline De $R \$ 4.685,00$ a $R \$ 6.559,00$ & 19 & $38,78 \%$ & 30 & $61,22 \%$ & 49 \\
\hline De $R \$ 6.559,00$ a $R \$ 8.433,00$ & 4 & $16,67 \%$ & 20 & $83,33 \%$ & 24 \\
\hline Mais de $\mathrm{R} \$ 8.433,00$ & 12 & $23,53 \%$ & 39 & $76,47 \%$ & 51 \\
\hline Sou praticante de esporte & Quant. & $\%$ & Quant. & $\%$ & \\
\hline Não & 81 & $42,63 \%$ & 109 & $57,37 \%$ & 190 \\
\hline Sim & 155 & $27,88 \%$ & 401 & $72,12 \%$ & 556 \\
\hline Sou sócio do Clube & Quant. & $\%$ & Quant. & $\%$ & \\
\hline Não & 158 & $33,91 \%$ & 308 & $66,09 \%$ & 466 \\
\hline Sim & 78 & $27,86 \%$ & 202 & $72,14 \%$ & 280 \\
\hline Sou membro da torcida organizada & Quant. & $\%$ & Quant. & $\%$ & \\
\hline Não & 224 & $32,23 \%$ & 471 & $67,77 \%$ & 695 \\
\hline Sim & $\begin{array}{l}12 \\
23,53 \%\end{array}$ & & 39 & $76,47 \%$ & 51 \\
\hline
\end{tabular}

Verifica-se na Tabela 3 que existem duas colunas que fazem a segregação de cada característica dos respondentes, sendo que a coluna com "sim" representa os indivíduos que se definiram como potenciais compradores dos produtos e serviços do Esporte Clube Vitória e, por outro lado, a coluna com "não" representa os torcedores que se declararam sem potencial para a compra de produtos e serviços do clube.

Os achados da Tabela 3 demonstram que o impacto de um patrocínio no potencial consumo não apresenta diferenças extremas entre o gênero feminino e o masculino. Ademais, os torcedores mais velhos apresentam maior probabilidade para consumo de produtos $e$ serviços do clube. Contudo, as diferenças mostram-se bastante sensíveis.

No que se refere à origem dos torcedores, verifica-se que a propensão de torcedores em se tornarem clientes em potencial é maior para aqueles que não nasceram em Salvador. Observa-se que o menor índice frente ao grau de instrução é verificado nos torcedores com 
ensino fundamental incompleto, e maior nos torcedores que cursam pós-graduação, bem como o maior nível de potencial comprador foi observado entre os torcedores que ganham até nove salários mínimos.

De maneira geral, os resultados são importantes para os patrocinadores dos clubes de futebol, ao passo que se observa que idade, renda, grau de escolaridade, prática de esportes, sócio do clube e torcida organizada são fatores de propensão para tornar o torcedor um consumidor das marcas que apoiam a equipe de futebol. Portanto, nos fatores relacionados ao maior engajamento com o futebol, como a prática de esportes, verifica-se uma maior propensão em tornar-se consumidor das marcas que apoiam a equipe.

Além disso, é possível inferir que o potencial para adquirir produtos dos patrocinadores é maior entre sócios e membros de torcida organizada. Contudo, apesar da grande propensão dos torcedores em se tornarem consumidores, a literatura aponta que esse potencial está relacionado com a percepção do torcedor sobre a relação entre a equipe e o patrocinador (Grohs et al., 2004).

Do mesmo modo, Grynberg e Rocha (2010) comentam que o impacto de um patrocínio nos torcedores não é homogêneo, ou seja, sofre influência de fatores relacionados ao nível de engajamento com a equipe. Nesse contexto, conhecer o público-alvo é relevante para que os patrocinadores explorem os resultados do apoio financeiro à equipe. Assim, a percepção dos torcedores sobre o engajamento da equipe em campo pode se sobressair aos fatores indivíduos apresentados nesta pesquisa. Esse fator precisa ser delineado pelo marketing esportivo e por seus patrocinadores na hora de ofertar produtos e serviços do clube de futebol.

A Tabela 4 demonstra os possíveis fatores explicativos do consumo de produtos e serviços relacionados aos clubes de futebol:

Tabela 4

Estatística descritiva dos fatores explicativos do consumo de produtos e serviços pelos torcedores de equipes de futebol

\begin{tabular}{|c|c|c|c|c|c|c|}
\hline \multirow{2}{*}{\multicolumn{2}{|c|}{ Fatores explicativos do consumo de produtos e serviços }} & \multicolumn{5}{|c|}{ Escala Likert } \\
\hline & & 1 & 2 & 3 & 4 & 5 \\
\hline \multirow[b]{2}{*}{ Exposição } & Acompanho os jogos do Vitória no Barradão. & $8,97 \%$ & $11,11 \%$ & $20,88 \%$ & $18,74 \%$ & $40,29 \%$ \\
\hline & $\begin{array}{l}\text { Quando o jogo é em outra cidade, assisto } \\
\text { pela televisão. }\end{array}$ & $2,01 \%$ & $1,87 \%$ & $4,95 \%$ & $13,12 \%$ & $78,05 \%$ \\
\hline \multirow{4}{*}{ Envolvimento } & $\begin{array}{l}\text { Antes ou depois do jogo, acompanho discus- } \\
\text { sões e reportagens do tipo "mesas- redondas" } \\
\text { e "melhores momentos". }\end{array}$ & $5,09 \%$ & $7,63 \%$ & $14,06 \%$ & $21,15 \%$ & $52,07 \%$ \\
\hline & $\begin{array}{l}\text { Depois do jogo, costumo participar de discus- } \\
\text { sões com amigos. }\end{array}$ & $3,48 \%$ & $4,55 \%$ & $16,33 \%$ & $19,68 \%$ & $55,96 \%$ \\
\hline & $\begin{array}{l}\text { Quando o Vitória perde, fico chateado ou } \\
\text { irritado no dia seguinte ao jogo? }\end{array}$ & $4,15 \%$ & $5,62 \%$ & $10,71 \%$ & $14,32 \%$ & $65,19 \%$ \\
\hline & $\begin{array}{l}\text { Quando vejo alguém criticando o Vitória } \\
\text { (como imprensa, amigos, etc.), sinto-me } \\
\text { incomodado. }\end{array}$ & $3,48 \%$ & $4,95 \%$ & $11,38 \%$ & $15,13 \%$ & $65,06 \%$ \\
\hline
\end{tabular}




\begin{tabular}{|c|c|c|c|c|c|c|}
\hline \multirow{2}{*}{\multicolumn{2}{|c|}{ Fatores explicativos do consumo de produtos e serviços }} & \multicolumn{5}{|c|}{ Escala Likert } \\
\hline & & 1 & 2 & 3 & 4 & 5 \\
\hline \multirow{3}{*}{$\begin{array}{l}\text { Domínio } \\
\text { futebol }\end{array}$} & Eu adoro futebol. & $0,94 \%$ & $0,54 \%$ & $3,35 \%$ & $8,57 \%$ & $86,61 \%$ \\
\hline & $\begin{array}{l}\text { Costumo pensar, ler ou falar sobre futebol } \\
\text { diariamente. }\end{array}$ & $1,61 \%$ & $2,68 \%$ & $8,84 \%$ & $19,68 \%$ & $67,2 \%$ \\
\hline & Eu assisto futebol sempre que posso. & $1,07 \%$ & $2,68 \%$ & $5,09 \%$ & $14,19 \%$ & $76,97 \%$ \\
\hline \multirow{2}{*}{ Similaridade } & $\begin{array}{l}\text { Quando assisto aos jogos do Vitória, vejo } \\
\text { produtos dos patrocinadores sendo utilizados } \\
\text { pelos atletas. }\end{array}$ & $5,09 \%$ & $9,64 \%$ & $25,7 \%$ & $19,28 \%$ & $40,29 \%$ \\
\hline & $\begin{array}{l}\text { As ideias que eu associo aos patrocinadores } \\
\text { são semelhantes às ideias que eu associo ao } \\
\text { Vitória. }\end{array}$ & $12,72 \%$ & $13,12 \%$ & $31,99 \%$ & $23,43 \%$ & $18,74 \%$ \\
\hline
\end{tabular}

Nota. 1 - Discordo totalmente; 2 - Discordo parcialmente; 3 - Não concordo e nem discordo; 4 - Concordo parcialmente; 5 - Concordo totalmente.

Conforme a Tabela 4, conclui-se que grande parte dos respondentes acompanham os jogos pela televisão quando não assistem no estádio, corroborando Souza (1996) a respeito do fenômeno cultural, em que há um grande engajamento na sociedade em acompanhar jogos de futebol. Percebe-se, também, que existe uma preferência dos torcedores em acompanharem os jogos da equipe pelos meios de comunicação ao invés de irem ao estádio.

A maior parcela dos respondentes está disposta a defender a equipe quando esta está sendo criticada, e costumam ficar chateados ou irritados quando o clube tem derrotas. Por outro lado, verifica-se uma menor participação dos respondentes com relação aos debates e reportagens sobre informações que antecipam as partidas ou depois dos jogos. Sob a mesma perspectiva, a dimensão de domínio de futebol se apresenta forte, principalmente nos fatores que envolvem a adoração pelo futebol e em assistir as partidas do clube. Por outro lado, na similaridade, observa-se que a maioria dos entrevistados não associam os produtos dos patrocinadores que estão sendo utilizados pelos atletas nas partidas de futebol e tampouco associam os patrocinadores às mesmas virtudes e ideias que são relacionadas ao Esporte Clube Vitória.

Conclui-se que a similaridade dos torcedores com os patrocinadores pode ser um fator de preocupação às marcas que esperam um retorno pelo patrocínio de clubes de futebol. Contudo, Grynberg e Rocha (2010) justificam que a percepção dos torcedores, normalmente, é construída no longo prazo, e sua lembrança sobre o patrocinador tem sido efetivada com o passar do tempo. Nesse limiar, sugere-se que o retorno sobre os investimentos de patrocinadores seja no longo prazo, sendo necessários anos consecutivos de patrocínio em um clube para que seus torcedores percebam similaridade do clube com o respectivo patrocinador.

Nesse contexto, verifica-se que podem existir outros fatores que explicam a probabilidade de consumo dos produtos de patrocinadores das equipes de futebol. Grynberg e Rocha (2010) apontam que o interesse por futebol (domínio) e o interesse em assistir esportes 
pela televisão têm maior capacidade de explicar a variação do recall dos patrocinadores da Seleção Brasileira de Futebol, e que a percepção de similaridade contribui de formas distintas para cada patrocinador. Enquanto, na pesquisa de Pacheco (2017), os torcedores com alta frequência de participação no estádio e os torcedores que pensam, leem e falam sobre futebol diariamente têm maior probabilidade para o consumo de bens e serviços do clube.

Esses achados confirmam os principais motivadores para o reconhecimento ou lembrança favorável com relação ao investidor, que são: exposição por meio de mensagens positivas; envolvimento e interesse que geram uma relação de identificação; e similaridade pelo estreitamento da relação patrocinador e patrocinado (Gwinner \& Swanson, 2003; Grohs et al., 2004; Grynberg \& Rocha, 2010).

A Tabela 5 apresenta a visão dos torcedores sobre o recall dos patrocinadores do clube, o que evidencia o reconhecimento sobre os patrocinadores Máster, em épocas distintas, ou seja, em anos de importantes conquistas e em períodos sem grandes resultados:

Tabela 5

Estatística descritiva dos torcedores sobre o recall dos patrocinadores Máster

\begin{tabular}{|c|c|c|}
\hline \multicolumn{3}{|c|}{$\begin{array}{c}\text { Na sua visão, quem é o patrocinador Máster do Vitória em 2017? Patrocinador Máster - marca em } \\
\text { destaque na camisa de jogo }\end{array}$} \\
\hline Caixa Econômica Federal @ & 668 & $89,54 \%$ \\
\hline Topper & 41 & $5,5 \%$ \\
\hline Não sabem & 5 & $0,67 \%$ \\
\hline Outras respostas & 32 & $4,29 \%$ \\
\hline \multicolumn{3}{|c|}{ No título do campeonato baiano de 2013, qual dessas empresas era o patrocinador Máster? } \\
\hline Caixa Econômica Federal & 124 & $16,62 \%$ \\
\hline Habib's & 31 & $4,16 \%$ \\
\hline Magazine Luiza & 14 & $1,88 \%$ \\
\hline Tim & 9 & $1,21 \%$ \\
\hline OAS@ & 565 & $75,74 \%$ \\
\hline Não sabiam & 3 & $0,4 \%$ \\
\hline \multicolumn{3}{|c|}{ No título do campeonato baiano de 2016, qual dessas empresas era o patrocinador Máster? } \\
\hline Caixa Econômica Federal @ & 681 & $91,29 \%$ \\
\hline Guara Mix & 2 & $0,27 \%$ \\
\hline Habib's & 5 & $0,67 \%$ \\
\hline Magazine Luiza & 2 & $0,27 \%$ \\
\hline OAS & 14 & $1,88 \%$ \\
\hline Puma & 2 & $0,27 \%$ \\
\hline Tim & 9 & $1,21 \%$ \\
\hline Não sabiam & 31 & $4,16 \%$ \\
\hline
\end{tabular}

Conforme a Tabela 5, o grande percentual de torcedores que tiveram lembrança sobre a marca mostra o alto índice de recall aos patrocinadores do clube. Aponta-se, assim, 
que a execução dos escopos principais do patrocinador (promoção da imagem, aumento de vendas, construção de um relacionamento), conforme Grynberg e Rocha (2010), produz resultados positivos às marcas.

Destaca-se que em 2017 a equipe do Vitória havia renovado seu patrocínio com a Caixa Econômica federal, prorrogando por mais um período o patrocínio Máster da equipe. Nessa pergunta, $89,54 \%$ dos torcedores responderam corretamente quem era o patrocinador Máster da equipe. Por outro lado, verifica-se que 5,5\% dos torcedores citaram a Topper como patrocinadora Máster. Os resultados da pesquisa de Grynberg e Rocha (2010) também mostraram alto índice de reconhecimento da marca esportiva entre os torcedores; uma característica que explica esse efeito está na similaridade entre o patrocinador e a equipe esportiva.

No campeonato baiano de 2013, o patrocinador Máster da equipe era a empresa do ramo de engenharia OAS, contudo, apesar do lapso temporal entre 2013 e a da ta de aplicação do questionário, a presença do título revelou um fator contributivo para o reconhecimento do patrocinador Máster do período, visto que 75,74\% responderam corretamente à pergunta. Por fim, em 2016 o patrocinador Máster da equipe também era a Caixa Econômica Federal; 91,29\% dos entrevistados responderam corretamente à pergunta, o percentual foi superior à primeira pergunta, que se referia ao período imediatamente anterior ao ano de aplicação do questionário.

Conclui-se que o patrocínio Máster mantido por vários anos consecutivos faz com que haja maior recall da marca, fato que corrobora Grynberg e Rocha (2010), os quais indicaram que a percepção dos torcedores pela marca patrocinadora de um clube de futebol tende a ocorrer no longo prazo. Esse resultado tem similaridade com a exposição de Tavares, Oliveira, Oliveira, \& Felizola (2009), na qual discorreram sobre a parceria entre a Petrobras e o Clube de Regatas do Flamengo, que perdurou por 25 anos, a mais duradoura da história do futebol brasileiro. A Petrobras conquistou grande recall para a sua marca de lubrificantes Lubrax, que esteve na parte frontal do uniforme rubro-negro por 22 anos, o que promoveu a associação da marca com o uniforme do clube e assim também denota uma imagem de solidez, confiabilidade e continuidade à empresa patrocinadora. Portanto, comprova-se que a marca consolida seu recall com os torcedores para aumentar o volume de vendas atrás do longo prazo.

A Tabela 6 apresenta a regressão logística que estima as relações entre os fatores explicativos do consumo de bens e serviços também relacionados ao efeito do recall do patrocínio Máster nos fatores explicativos do consumo de bens e serviços do clube de futebol: 
Tabela 6

Regressão logística dos modelos de previsão do consumo de bens e serviços do clube de futebol

\begin{tabular}{|c|c|c|c|c|c|c|c|}
\hline \multicolumn{2}{|c|}{ Variáveis independentes } & & & \multicolumn{2}{|c|}{ CONS } \\
\hline \multirow[b]{2}{*}{ Constructo } & \multirow[b]{2}{*}{ Evento } & \multicolumn{2}{|c|}{ Equação 1} & \multicolumn{2}{|c|}{ Equação 2} & \multicolumn{2}{|c|}{ Equação 3} \\
\hline & & B & Sig. & B & Sig. & B & Sig. \\
\hline \multirow{8}{*}{$\begin{array}{l}\text { Caract. } \\
\text { Respond. }\end{array}$} & GEN & 0,037 & 0,922 & & & & \\
\hline & IDADE & 0,119 & 0,269 & & & & \\
\hline & ORG & $-0,240$ & 0,213 & & & & \\
\hline & ESCO & 0,051 & 0,545 & & & & \\
\hline & RENDA & $-0,056$ & 0,456 & & & & \\
\hline & PRAT & 0,702 & $0,001^{*}$ & 0,616 & $0,002^{*}$ & 0,647 & $0,001^{*}$ \\
\hline & SOC & 0,030 & 0,888 & & & & \\
\hline & TORC & 0,533 & 0,168 & & & & \\
\hline \multirow{3}{*}{ Recall } & ESP & 0,234 & 0,396 & & & & \\
\hline & OAS & 0,361 & $0,079^{* *}$ & 4,845 & $0,038^{*}$ & & \\
\hline & CAIXA & 0,489 & 0,110 & & & 1,605 & 0,497 \\
\hline \multirow{6}{*}{ Exposição } & EXPI & 0,031 & 0,695 & $-0,157$ & 0,353 & $-0,098$ & 0,710 \\
\hline & EXPI*OAS & & & 0,255 & 0,169 & & \\
\hline & EXPI*CAIXA & & & & & 0,152 & 0,577 \\
\hline & EXP2 & 0,016 & 0,886 & 0,125 & 0,542 & 0,350 & 0,412 \\
\hline & EXP2*OAS & & & $-0,224$ & 0,368 & & \\
\hline & EXP2 ${ }^{*}$ CAIXA & & & & & $-0,371$ & 0,402 \\
\hline \multirow{12}{*}{ Envolvimento } & ENV1 & 0,142 & $0,078^{* *}$ & 0,008 & 0,962 & 0,446 & 0,194 \\
\hline & ENVI*OAS & & & 0,211 & 0,288 & & \\
\hline & ENVI ${ }^{*}$ CAIXA & & & & & $-0,339$ & 0,338 \\
\hline & ENV2 & 0,038 & 0,684 & 0,214 & 0,240 & 0,296 & 0,538 \\
\hline & ENV2*OAS & & & $-0,220$ & 0,300 & & \\
\hline & ENV $2^{*}$ CAIXA & & & & & $-0,281$ & 0,566 \\
\hline & ENV3 & 0,216 & $0,013^{*}$ & 0,333 & $0,053^{*}$ & 0,047 & 0,874 \\
\hline & ENV3*OAS & & & $-0,152$ & 0,451 & & \\
\hline & ENV $3^{*}$ CAIXA & & & & & 0,191 & 0,541 \\
\hline & ENV4 & $-0,062$ & 0,507 & $-0,392$ & $0,058^{* *}$ & $-1,348$ & $0,003^{*}$ \\
\hline & ENV4*OAS & & & 0,461 & $0,049^{*}$ & & \\
\hline & ENV4*CAIXA & & & & & 1,378 & $0,003^{*}$ \\
\hline \multirow{9}{*}{ Domínio futebol } & DF1 & $-0,086$ & 0,633 & 0,515 & 0,312 & 0,015 & 0,980 \\
\hline & DFI*OAS & & & $-0,645$ & 0,239 & & \\
\hline & DFI*CAIXA & & & & & $-0,109$ & 0,868 \\
\hline & DF2 & 0,088 & 0,493 & 0,456 & $0,049^{*}$ & 0,139 & 0,783 \\
\hline & DF2*OAS & & & $-0,544$ & $0,051^{*}$ & & \\
\hline & DF2*CAIXA & & & & & $-0,084$ & 0,872 \\
\hline & DF3 & $-0,161$ & 0,247 & $-0,108$ & 0,727 & $-0,115$ & 0,823 \\
\hline & DF3*OAS & & & $-0,116$ & 0,742 & & \\
\hline & DF3*CAIXA & & & & & $-0,096$ & 0,859 \\
\hline
\end{tabular}




\begin{tabular}{|c|c|c|c|c|c|c|c|}
\hline \multicolumn{2}{|c|}{ Variáveis independentes } & \multirow{2}{*}{\multicolumn{2}{|c|}{$\frac{\text { CONS }}{\text { Equação } 1}$}} & \multirow{2}{*}{\multicolumn{2}{|c|}{$\begin{array}{c}\text { CONS } \\
\text { Equação } 2\end{array}$}} & \multicolumn{2}{|c|}{ CONS } \\
\hline \multirow[b]{2}{*}{ Constructo } & \multirow[b]{2}{*}{ Evento } & & & & & \multicolumn{2}{|c|}{ Equação 3} \\
\hline & & B & Sig. & B & Sig. & B & Sig. \\
\hline \multirow{6}{*}{ Similaridade } & SIMI & 0,144 & $0,069^{* *}$ & 0,084 & 0,605 & 0,779 & $0,045^{*}$ \\
\hline & SIMI*OAS & & & 0,090 & 0,629 & & \\
\hline & SIMI*CAIXA & & & & & $-0,653$ & 0,100 \\
\hline & SIM2 & 0,451 & $0,000^{*}$ & 0,479 & $0,004^{*}$ & 0,583 & $0,042^{*}$ \\
\hline & SIM2*OAS & & & 0,017 & 0,930 & & \\
\hline & SIM2*CAIXA & & & & & $-0,126$ & 0,674 \\
\hline Constante & & $-3,630$ & $0,000^{*}$ & $-6,339$ & $0,003^{*}$ & $-3,676$ & $0,090^{* *}$ \\
\hline $\mathrm{R}^{2}$ & & 0,204 & & 0,227 & & 0,224 & \\
\hline $\begin{array}{l}\text { Potencial de } \\
\text { dor }\end{array}$ & do potencial compra- & 72,5 & & 73,7 & & 73,70 & \\
\hline
\end{tabular}

Verifica-se na Tabela 5 que os modelos testados apresentaram robustez na regressão logística, ao passo que se mostraram significantes e com um "Nagelkerke" de 0,204, 0,227 e 0,224 , respectivamente. Esse achado demonstra que as variáveis independentes dos modelos explicam em média entre $20 \%$ e $23 \%$ da variação no potencial de consumo dos produtos e serviços pelos torcedores do Esporte Clube Vitória. Além disso, os achados indicam que o potencial de acerto do potencial comprador apresentou uma variação de $72,5 \%$ a $73,7 \%$. Portanto, é possível suportar que as variáveis demonstradas pela pesquisa são importantes na observação daqueles que pretendem alavancar as vendas dos produtos e serviços dos clubes de futebol.

Destaca-se que a Equação 1 representa os possíveis fatores explicativos do potencial de consumo dos produtos e serviços do Clube de futebol. Assim, os achados sugerem que praticar esportes faz com que seja aumentado o potencial de consumo dos torcedores por produtos do Esporte Clube Vitória. Esse fator pode ser explicado porque os torcedores que praticam esporte são aqueles que adquirem em maior probabilidade produtos esportivos.

Além disso, os resultados indicam que o recall do patrocínio Máster da OAS, no ano do título do campeonato baiano de 2013, esteve associado positivamente com o maior consumo dos produtos e serviços do Esporte Clube Vitória. De maneira geral, pode-se inferir que em momentos de títulos, o recall prevalece para impulsionar a venda de produtos e serviços dos clubes de futebol. Os achados oferecem suporte para a inferência de Marques (2007), o qual apontou que o futebol fornece grande influência nas relações de consumo de seus torcedores, em que quanto maior o engajamento com os patrocinadores, maiores podem ser os benefícios para as empresas que apostarem na equipe. Portanto, a conquista de títulos faz emergir um maior reconhecimento dos torcedores frente à marca patrocinadora do Clube.

Ademais, verifica-se que acompanhar as discussões e reportagens antes ou depois do jogo (ENV1) e ficar chateado ou irritado no dia seguinte ao jogo (ENV3) são fatores 
que influenciam o potencial de consumo dos torcedores pelos produtos e serviços do Esporte Clube Vitória. Dessa forma, considera-se que o envolvimento do torcedor com o clube se torna fator explicativo do consumo de produtos e serviços. Por fim, a similaridade também se demonstrou fator explicativo do consumo de produtos ou serviços, visto que os torcedores que percebem os patrocinadores quando assistem aos jogos do Vitória (SIMI) e aqueles que associam os patrocinadores às ideias do Vitória (SIM2) estão relacionados com o consumo de produtos e serviços do Clube. Esses achados demonstram o potencial do patrocínio na alavancagem das vendas de seus produtos, sendo útil aos dirigentes de futebol e às empresas que buscam um retorno com a inserção de suas marcas divulgadas nos clubes de futebol.

Esse fator, segundo Grynberg e Rocha (2010), contribui para que os torcedores se tornem consumidores dos produtos das empresas patrocinadoras, a ligação e a similaridade do clube com a empresa contribuem efetivamente para essa propensão. Grynberg e Rocha (2010) destacam que os clubes de futebol, pela característica de contato diário, facilitam o reconhecimento e a lembrança dos produtos dos patrocinadores; o que contribui para tal percepção é a característica regional da equipe, que possibilita maior aproximação com seu torcedor. De acordo com Mattar (2013), o esporte tem o poder de influenciar o comportamento de seus torcedores, contudo, a lealdade dos torcedores não se traduz linearmente em consumo.

A Equação 2 verifica o efeito moderador do recall pelo patrocínio da OAS nos fatores explicativos do consumo de bens e serviços. Assim, os resultados indicam que o torcedor que verifica alguém criticando o Vitória e se sente incomodado (ENV4) está relacionado negativamente ao potencial de consumo, contudo, quando a variável está associada ao recall do patrocínio da OAS, o fator torna-se positivamente relacionado ao potencial de consumo.

Resultado complementar foi encontrado pela Equação 3 no recall do patrocínio Máster da Caixa Econômica Federal, o qual exerceu efeito na relação entre os torcedores incomodados com as críticas feitas ao Clube e o potencial de consumo dos produtos e serviços. Nesse sentido, conclui-se que o recall do patrocínio Máster pela OAS e Caixa Econômica Federal fez com que os torcedores incomodados com as críticas dos amigos ao Vitória se tornassem potenciais consumidores dos produtos e serviços do Esporte Clube Vitória.

De forma geral, por meio deste estudo, é possível inferir que os torcedores praticantes de esportes, acompanhantes das discussões e reportagens dos jogos e os que se afetam emocionalmente com os resultados apresentam propensão para o consumo de produtos $e$ serviços do Esporte Clube Vitória. Sugere-se que a conquista de um título provoca aumento no consumo dos produtos e serviços, o que fortifica a relação de similaridade entre os patrocinadores e seus respectivos patrocinados. Assim, os critérios que enfatiza o futebol, mencionados por Carvalho (2001), que são eficiência, rentabilidade e competitividade, demostram ser os pilares para o reconhecimento da marca patrocinadora no futebol. 


\section{CONSIDERAÇÕES FINAIS}

O objetivo desta investigação foi identificar a relação do recall do patrocínio Máster nos fatores explicativos para o consumo de bens e serviços do Esporte Clube Vitória. Para tanto, adotou-se a pesquisa descritiva para os objetivos, de levantamento nos procedimentos e, por fim, de cunho quantitativo na abordagem do problema.

Como resultado, verificou-se que a propensão dos torcedores em se tornarem clientes em potencial é maior quando estes não nasceram em Salvador, bem como sócios do Clube, membros de torcida organizada e praticantes de esportes. Esses achados podem oferecer oportunidade para a ampliação de ações com a intenção de explorar esses públicos. Como implicações gerenciais, percebe-se como diferenciais à empresa que almeja se destacar e gravar sua marca na mente dos torcedores. Nesse quesito, maiores ações de patrocínio esportivo devem ser realizadas nos estádios e em seus arredores, antes, durante e depois da partida.

De forma igual, as implicações acadêmicas versam em determinar que as características dos indivíduos podem ser utilizadas como fatores explicativos do hábito de consumo dos torcedores, bem como pelo fato de que o recall do patrocínio Máster pode exercer um efeito de moderação sobre a relação entre os fatores explicativos e o hábito de consumo dos torcedores frente aos produtos ofertados pelos clubes de futebol.

Como fatores explicativos, identificou-se na Equação 1 que praticar esportes, acompanhar as discussões e reportagens antes ou depois do jogo, ficar chateado ou irritado no dia seguinte ao jogo em que o Vitória perder e a similaridade influenciam positivamente o potencial de consumo dos torcedores pelos produtos e serviços do Esporte Clube Vitória.

Nessas circunstâncias, o marketing esportivo deve ser efetivo em suas ações para a manutenção dos consumidores (torcedores) praticantes de esportes que possuem recall do patrocínio Máster, envolvimento e similaridade com o Clube. Por outro lado, o marketing esportivo deve oferecer outros diferenciais aos torcedores sócios dos clubes e representantes das torcidas organizadas, bem como aqueles com domínio sobre futebol e com alta exposição do Clube para buscar entender o que explica não serem fatores que impactam a potencialização do consumo de produtos e serviços do Vitória.

Conclui-se que o recall do patrocínio Máster se torna mais efetivo pelo estímulo, como ocorrido no recall da empresa OAS e da Caixa Econômica Federal, em que ambos podem ter exercido efeito moderador, do envolvimento para o consumo dos produtos e serviços, em razão dos títulos do campeonato baiano. Destaca-se que o recall espontâneo não foi apresentado nos resultados da pesquisa por não existir relação alguma com o consumo direto de bens e serviços e tampouco com o intermediador dos fatores explicativos para o consumo de bens e serviços. Esse resultado corrobora Grynberg e Rocha (2010) que destacam o recall sendo 
definido em decorrência da memória e uma pessoa que fica exposta a um estímulo. Assim, quanto maior o estímulo, por exemplo, pelo título de um campeonato, maior será a capacidade de retenção e comunicação da marca com os torcedores (Grynberg \& Rocha, 2010).

Este estudo contribui por determinar que as características dos indivíduos podem ser utilizadas como fatores explicativos do hábito de consumo dos torcedores, bem como pelo fato de que o recall do patrocínio Máster pode exercer um efeito de moderação sobre a relação entre os fatores explicativos e o hábito de consumo dos torcedores frente aos produtos ofertados pelos clubes de futebol.

Ao final do estudo foram enviados ao Clube de futebol os resultados do estudo e as considerações dos pesquisadores com o intuito de aprimorar suas estratégias de marketing.

As limitações desta investigação poderão oferecer oportunidade à continuidade das investigações sobre a temática. Vale mencionar que este estudo buscou compreender a realidade desse Clube específico. Futuras investigações podem explorar a realidade de clubes de receitas maiores e menores com o intuito de comparar os resultados. Outro aspecto versa que o estudo se limitou a respondentes em rede social. Nesse ponto, futuras investigações podem buscar respondentes que frequentam o estádio.

\section{REFERÊNCIAS}

Adamson, G., Jones, W., \& Tapp, A. (2006). From CRM to FRM: Applying CRM in the football industry. Journal of Database Marketing \& Customer Strategy Management, 13(2), 156-172.

Agresti, A., \& Finlay, B. (2012). Métodos estatísticos para as ciências sociais. Porto Alegre: Penso.

Benazzi, J. R. D. S. C., \& Borges, C. N. (2009). Emoção, Exposição e Vendas: Análise do patrocínio realizado por marcas de artigos esportivos no futebol brasileiro. Anais do Simpósio de Excelência em Gestão e Tecnologia, Resende, 6.

Bezerra, M. F., \& Luna, C. (2017). Uma análise sobre as mulheres em consumir futebol. Caderno Profissional de Marketing-UNIMEP, 5(3), 61-74.

Carvalho, Y. M. (2001). O mito da atividade física e saúde. (3a ed.). São Paulo: Hucitec.

Esporte Clube Vitória. (2017). Demonstrações dos resultados - 2017. Recuperado de http://www.ecvitoria.com.br/wpcontent/uploads/2018/04/1987812479_4f9810ab7lc32d$30 f 4 e 2442 f 589272 c e . p d f$ 
Fleury, F. A., Alejandro, T. B., \& Feldmann, P. R. (2014). Considerações teóricas acerca do composto de marketing esportivo. PODIUM Sport, Leisure and Tourism Review, 3(1), 1-11.

Forbes Brasil. (2018, Agosto 1). Os 50 times de futebol mais valiosos da América em 2018. Recuperado de https://forbes.uol.com.br/listas/2018/08/os-50-times-de-futebol-mais-valiosos-da-america-em-2018/

Grohs, R., Wagner, U., \& Vsetecka, S. (2004). Assessing the effectiveness of sport sponsorships - An empirical examination. Schmalenbach business review, 56(2), 119-138.

Grynberg, C. A., \& Rocha, A. L. P. da (2010). Modelos de mensuração do recall de patrocínio esportivo nos consumidores: Uma aplicação sobre os patrocinadores da seleção brasileira de futebol. REAd - Revista Eletrônica de Administração, 16(3), 564-588.

Gwinner, K. P., \& Eaton, J. (1999). Building brand image through event sponsorship: The role of image transfer. Journal of advertising, 28(4), 47-57.

Gwinner, K. P., \& Swanson, S. R. (2003). A model of fan identification: Antecedents and sponsorship outcomes. Journal of services marketing, 17(3), 275-294.

Hooley, G. J., Saunders, J. A., \& Piercy, N. F. (2005). Estratégia de marketing e posicionamento competitivo. London: Financial Times.

leg Sponsorship Report. (2004). Sponsorship Spending in North America. Chicago: IEG.

Javalgi, R. G., Traylor, M. B., Gross, A. C., \& Lampman, E. (1994). Awareness of sponsorship and corporate image: An empirical investigation. Journal of advertising, 23(4), 47-58.

Kotler, P., \& Keller, K. L. (2006). Administração de marketing - A bíblia do marketing. (12a ed.). São Paulo: Saraiva.

Malagrino, F. A. F. (2011). Gestão das marcas dos clubes de futebol: Como o marketing esportivo potencializa o consumo do torcedor (Dissertação de mestrado). Pontifícia Universidade Católica de São Paulo, São Paulo.

Marques, R. F. R. (2007). Esporte e Qualidade de Vida: Reflexão sociológica (Dissertação de Mestrado). Universidade Estadual de Campinas, Campinas.

Mattar, F. N. (2013). Indústria do Esporte e seu Ambiente de Negócios. Gestão de Negócios Esportivos, 1-31. 
Meenaghan, T. (2001). Understanding sponsorship effects. Psychology \& Marketing, 18(2), 95-122.

Morgan, M. J., \& Summers, J. (2008). Marketing esportivo (Vertice Translate Trad. \& J. C. Golçalves Rev. Téc.). São Paulo: Saraiva.

Pacheco, G. (2017). A relação entre o patrocínio de clubes de futebol e o consumo de bens e serviços (Dissertação de mestrado). Universidade Regional de Blumenau, Blumenau.

Relatório Final do Plano de Modernização do Futebol Brasileiro. (2000). Rio de Janeiro: Fundação Getúlio Vargas e Confederação Brasileira de Futebol.

Rocha, A. L. P., \& Campos, S. F. (2010). Uma avaliação das características mais relevantes em projetos de patrocínio de eventos e sua relação com os objetivos almejados. REAd Revista Eletrônica de Administração, 16(1).

Russi, E. (2014). Patrocínio Esportivo em Clubes Emergentes como Estratégia de Marketing para Empresas de Grande Porte (Dissertação de mestrado em Administração). Universidade Regional de Blumenau, Blumenau.

Scharf, E. R. (2010). O patrocínio do futebol como ferramenta do marketing esportivo para a construção de brand awareness 10.5752/P. 1984-6606.2010 v10n23p80. Revista Economia \& Gestão, 10(23), 80-99.

Souza, M. A. (1996). Gênero e raça: A nação construída pelo futebol brasileiro. Cadernos pagu, (6/7), 109-152.

Sport Business. (2007). Sport Business in Numbers. Informe 2007, 3-7.

Tavares, B. S., Oliveira, F. N., Oliveira, R. A. B., \& Felizola, M. P. M. (2009). Times de Futebol e Potencial Mercadológico: Um estudo de caso sobre o Clube de Regatas Flamengo. Anais do Congresso de Ciências da Comunicação na Região Centro-Oeste, Brasília, DF, 11.

Varadarajan, R. (2011). Marketing strategy: Discerning the relative influence of product and firm characteristics. AMS review, 1(1), 32-43.

Zinger, J. T., \& O'Reilly, N. J. (2010). An examination of sports sponsorship from a small business perspective. International Journal of Sports Marketing and Sponsorship, 11(4), 14-32. 


\section{Como citar este artigo:}

\section{ABNT}

SILVA, T. B. J. et al. Efeito do recall do patrocínio Máster nos fatores de consumo de bens e serviços de um clube de futebol. RACE, Revista de Administração, Contabilidade e Economia, Joaçaba: Ed. Unoesc, v. 18, n. 1, p. 113-136, jan./abr. 2019. Disponível em: https://portalperiodicos.unoesc.edu.br/race. Acesso em: dia/mês/ano.

\section{APA}

Silva, T. B. J., Lay, L. A., Dal Magro, C. B., Rizzi, D. I., \& Ferla, R. (2019). Efeito do recall do patrocínio Máster nos fatores de consumo de bens e serviços de um clube de futebol. RACE, Revista de Administração, Contabilidade e Economia, 18(1), 113-136. Recuperado de http://editora.unoesc.edu.br/index.php/race 